Sādhanā Vol. 38, Part 3, June 2013, pp. 429-445. (c) Indian Academy of Sciences

\title{
Experimental investigation of cutting parameters influence on surface roughness and cutting forces in hard turning of X38CrMoV5-1 with CBN tool
}

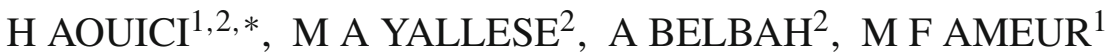 \\ and $\mathrm{MELBAH}^{2}$ \\ ${ }^{1}$ ENST-ex CT siège DG. SNVI, Route Nationale $N^{\circ} 5$ Z.I. Rouiba, Algeria \\ ${ }^{2}$ Mechanics and Structures Laboratory, (LMS), May 8th 1945 University of Guelma, \\ P.O. Box 401, 24000 Guelma, Algeria \\ e-mail: aouici_hamdi@yahoo.fr
}

MS received 7 September 2011; revised 31 October 2012; accepted 26 April 2013

\begin{abstract}
This experimental investigation was conducted to determine the effects of cutting conditions on surface roughness and cutting forces in hard turning of X38CrMoV5-1. This steel was hardened at $50 \mathrm{HRC}$ and machined with CBN tool. This is employed for the manufacture of helicopter rotor blades and forging dies. Combined effects of three cutting parameters, namely cutting speed, feed rate and depth of cut, on the six performance outputs-surface roughness parameters and cutting force components, are explored by analysis of variance (ANOVA). Optimal cutting conditions for each performance level are established. The relationship between the variables and the technological parameters is determined through the response surface methodology (RSM), using a quadratic regression model. Results show how much surface roughness is mainly influenced by feed rate and cutting speed. The depth of cut exhibits maximum influence on cutting force components as compared to the feed rate and cutting speed.
\end{abstract}

Keywords. Hard turning; RSM; CBN; ANOVA; cutting force; surface roughness.

\section{Introduction}

Hard turning is a process, in which materials in their hardened state (45-70 HRC) are machined with the single point cutting tools. This has become possible with the availability of the new cutting tool materials (cubic boron nitride and ceramics). Since a large number of operations are required to produce the finished product, if some of the operations can be combined, or eliminated, or can be substituted by the new process, product cycle time can be reduced and productivity can be improved. The traditional method of machining hardened materials includes

*For correspondence 
rough turning, heat treatment, and then grinding process. Hard turning eliminates the series of operations required to produce the component and thereby reducing the cycle time and hence resulting in productivity improvement (Bouacha et al 2010; Tamizharasan et al 2006).

Cutting forces are the background for the evaluation of the necessary power machining (choice of the electric motor). They are also used for dimensioning of machine tool components and the tool body. They influence the deformation of workpiece machined, its dimensional accuracy, chip formation and machining system stability (Fnides et al 2008).

Surface roughness plays an important role as it influences the fatigue strength, wear rate, coefficient of friction, and corrosion resistance of the machined components. In actual practice, there are many factors which affect the surface roughness, i.e., tool variables, workpiece hardness and cutting conditions. Tool variables include tool material, nose radius, rake angle, cutting edge geometry, tool vibration, tool point angle, etc. Theoretical surface roughness achievable based on tool geometry and feed rate is given approximately by the formula: $R a=0.032 f^{2} / r_{\varepsilon}$. In hard turning, surface finish has been found to be influenced by a number of factors such as feed rate, cutting speed, tool nose radius and tool geometry, cutting time, workpiece hardness, stability of the machine tool and the workpiece set up, etc. (Chen 2008; Sahin \& Motorcu 2005). Huang et al (2006) presented a thorough review that discusses CBN tool material microstructure, encountered wear patterns and tool wear rate modelling under hard turning. Lima et al (2005) investigated the machinability of hardened steels at different levels of hardness and using a range of cutting tool materials. More specifically, the machinability of hardened AISI 4340 high strength low alloy steel and AISI D2 cold work tool steel. The results indicated that when turning AISI 4340 steel the surface roughness of the machined parts was improved as cutting speed was elevated and deteriorated with feed rate. Depth of cut presented little effect on the surface roughness values. Dilbag \& Venkateswara (2007) have conducted the study on the influence of rake angle, cutting speed, feed rate and nose radius are primary influencing factors which effect the surface finish, the results indicated that the feed rate is a dominant factor affecting the surface roughness. Sahin \& Motorcu (2005) showed that the feed rate was main influencing factor on the surface roughness. It increased with increasing the feed rate but decreased with increasing the cutting speed and the depth of cut, respectively. Bouacha et al (2010) investigated the effect of cutting speed, feed rate and depth of cut on surface roughness and cutting forces using three level factorial design $\left(3^{3}\right)$ during machining of bearing steel (AISI 52100) with CBN tool. Results show how much surface roughness is mainly influenced by feed rate and cutting speed and that the depth of cut exhibits maximum influence on the cutting forces as compared to feed rate and cutting speed.

Thiele \& Melkote (1999) investigated the effect of cutting edge geometry on surface roughness in finish hard turning by cutting bars (28.6 mm diameter) of AISI 52100 steel at three different hardness values $(41 ; 47 ; 57 \mathrm{HRC})$. They used low-CBN inserts with four edge radius. The experiments were carried out using different feed rates $(0.05,0.10,0.15 \mathrm{~mm} / \mathrm{rev})$ and fixed cutting speeds $(121.9 \mathrm{~m} / \mathrm{min})$ and depth of cut $(0.254 \mathrm{~mm})$. The authors observed that the effect of the cutting edge hone on surface roughness decreases with increase in workpiece hardness. Also, they noted that the cutting edge geometry has a significant effect on the axial and radial cutting force components. Suresh et al (2002) studied a genetic algorithmic approach for optimizing the surface finish prediction model for cutting carbon steel. This approach gives minimum and maximum values of surface roughness and their respective optimal machining conditions. Horng et al (2008) developed a model for the prediction of surface roughness followed by an optimization model for the determination of optimal cutting conditions in machining austenitic Hadfield steel. The quadratic model of RSM associated with the sequential approximation optimization (SAO) 
method was used to find optimum values of machining parameters. Drawish (2000) studied the effect of the tools and cutting parameters on surface roughness of 718 nickel alloy. This work also showed that feed rate has the dominant effect on surface roughness amongst the parameters studied, irrespective of tool materials used. Yallese et al (2009) found that a cutting speed of $120 \mathrm{~m} / \mathrm{min}$ is an optimal value for machining 100Cr6 (60 HRC) using CBN7020. In addition, the feed rate effect on roughness is satisfactorily predicted by a power model deduced from experimental data. A correlation between surface roughness and tool wear is proposed for the usual cutting speed ranges. In an original work carried out by Çaydaş (2009), the effects of the cutting speed, feed rate, depth of cut, workpiece hardness, and cutting tool type on surface roughness, tool flank wear, and maximum tool-chip interface temperature during an orthogonal hard turning of hardened/tempered AISI 4340 steels were investigated. Dureja et al (2009) investigated the effect of cutting speed, depth of cut, workpiece hardness and feed rate on surface roughness and flank wear using a three-level factorial design, during machining of AISI H11 with a coatedmixed ceramic tool. The study indicated that feed rate and workpiece hardness are the most significant factors affecting the surface roughness. Singh \& Kumar (2006) studied on optimization of feed force through setting of optimal value of process parameters namely speed, feed and depth of cut in turning of EN24 steel with TiC coated tungsten carbide inserts. The authors used Taguchi's parameter design approach and concluded that the effect of depth of cut and feed in variation of feed force were affected more as compare to speed. Kirby et al (2004) developed the prediction model for surface roughness in turning operation. The regression model was developed by a single cutting parameter and vibrations along three axes were chosen for in-process surface roughness prediction system.

By using multiple regression and Analysis of Variance (ANOVA) a strong linear relationship among the parameters (feed rate and vibration measured in three axes) and the response (surface roughness) was found. The authors demonstrated that spindle speed and depth of cut might not necessarily have to be fixed for an effective surface roughness prediction model. Özel et al (2007) studied for prediction of surface roughness and tool flank wear by utilizing the neural network model in comparison with regression model. The data set from measured surface roughness and tool flank wear were employed to train the neural network models. Predictive neural network models were found to be capable of better predictions for surface roughness and tool flank wear within the range in between they were trained. Aouici et al (2010) studied on machining of slide-lathing grade X38CrMoV5-1 steel treated at $50 \mathrm{HRC}$ by a CBN 7020 tool to reveal the influences of cutting parameters: feed rate, cutting speed and depth of cut on cutting forces as well as on surface roughness. The authors found that tangential cutting force was very sensitive to the variation of cutting depth. It was observed that surface roughness was very sensitive to the variation of feed rate and that flank wear had a great influence on the evolution of cutting force components and on the criteria of surface roughness.

Our study aims to develop models, using the RSM approach, for predicting surface roughness parameters and cutting force components during machining of X38CrMoV5-1 steel with CBN7020. The RSM as employed in this investigation the relation-ship between various process parameters and the response factors within the desired limits. It is an efficient tool for designing the experiments and, by applying ANOVA and regression analysis, the response factors can be modelled in terms of input parameters. The developed model describes the interaction (single/two parameters) of various input parameters with respect to response factors. RSM has been proven to be a very powerful tool for solving optimization problems in manufacturing environments. The quadratic models of RSM with desirability function optimization have been used in this study to arrive at the optimal setting of machining parameters. 
Table 1. Chemical composition of X38CrMoV5-1steel.

\begin{tabular}{lc}
\hline Composition & $(\mathrm{Wt} \%)$ \\
\hline $\mathrm{C}$ & 0.35 \\
$\mathrm{Cr}$ & 5.26 \\
$\mathrm{Mo}$ & 1.19 \\
$\mathrm{~V}$ & 0.50 \\
$\mathrm{Si}$ & 1.01 \\
$\mathrm{Mn}$ & 0.32 \\
$\mathrm{~S}$ & 0.002 \\
$\mathrm{P}$ & 0.016 \\
Other components & 1.042 \\
$\mathrm{Fe}$ & 90.31 \\
\hline
\end{tabular}

\section{Experimental procedures}

\subsection{Material, workpiece and tool}

Turning experiments were performed in dry conditions using lathe type SN 40C with $6.6 \mathrm{KW}$ spindle power. The workpiece material was X38CrMoV5-1, hot work steel which is popularly used in hot form pressing. Its resistance to high temperature and its aptitude for polishing enable it to answer the most server requests in hot dieing and moulds under pressure. Its chemical composition is given in table 1 .

The workpiece is $80 \mathrm{~mm}$ in diameter and it is hardened to $50 \mathrm{HRC}$. Cutting insert is removable and offered eight squared working edges. The chosen CBN tool in commercially known as CBN7020 and it is essentially made of $57 \% \mathrm{CBN}$ and $35 \% \mathrm{Ti}(\mathrm{C}, \mathrm{N})$. Its standard designation is SNGA120408 S01020 and is manufactured by Sandvik. The physical properties of the CBN7020 tool are summarized in table 2.

Tool holder is codified as PSBNR $25 \times 25 \mathrm{~K} 12$ with a common active part tool geometry described by $\chi_{r}=+75^{\circ}, \lambda=-6^{\circ}, \gamma=-6^{\circ}$ and $\alpha=+6^{\circ}$. For three components measurement of cutting forces in $\mathrm{X}, \mathrm{Y}$ and $\mathrm{Z}$ directions were recorded using a standard quartz dynamometer (Kistler 9257B) allowing measurements from -5 to $5 \mathrm{KN}$. Instantaneous roughness criteria measurement ( $R a, R t$ and $R z$ ) for each cutting condition were obtained from a Surftest 201 Mitutoyo roughness meter coupled with a radius and moves linearly on the working surface. The length examined is $5.0 \mathrm{~mm}$ with a basic span of $0.8 \mathrm{~mm}$. The measured values of $R a$ are within the range 0.05 to $40 \mu \mathrm{m}$ while for $R t$ and $R z$, they lay between 0.3 and $160 \mu \mathrm{m}$. Roughness measurements were directly obtained on the same without disassembling the turned part in order to reduce uncertainties due to resumption operations. The measurements were repeated 3 times out of 3 generatrices equally positioned at $120^{\circ}$ and the result is an average of these values for a given machining pass.

Table 2. Physical properties of CBN7020 tool.

\begin{tabular}{lccccc}
\hline Material & $\begin{array}{c}\text { Hardness HV } \\
\left(\mathrm{daN} / \mathrm{mm}^{2}\right)\end{array}$ & $\begin{array}{c}\text { Tenacity } \\
\left(\mathrm{MPa} \mathrm{m}{ }^{1 / 2}\right)\end{array}$ & $\begin{array}{c}\text { Young's modulus } \\
(\mathrm{GPa})\end{array}$ & $\begin{array}{c}\text { Density } \\
\left(\mathrm{g} / \mathrm{cm}^{3}\right)\end{array}$ & $\begin{array}{c}\text { Grain size } \\
(\mu \mathrm{m})\end{array}$ \\
\hline CBN7020 & 2800 & 4.2 & 570 & 4.3 & 2.5 \\
\hline
\end{tabular}


Table 3. Assignment of the levels to the factors.

\begin{tabular}{lccc}
\hline Level & Cutting speed $V c(\mathrm{~m} / \mathrm{min})$ & Feed rate $f(\mathrm{~mm} / \mathrm{rev})$ & Depth of cut $a p(\mathrm{~mm})$ \\
\hline 1 & 120 & 0.08 & 0.15 \\
2 & 180 & 0.12 & 0.30 \\
3 & 240 & 0.16 & 0.45 \\
\hline
\end{tabular}

\subsection{Experiments design}

The response surface methodology (RSM) is the procedure for determining the relationship between the independent process parameters with the desired response and exploring the effect of these parameters on responses, including six steps (Chiang 2008). These are, in the order, (1) define the independent input variables and the desired responses with the design constants, (2) adopt an experimental design plan, (3) perform regression analysis with the quadratic model of RSM, (4) calculate the statistical analysis of variance (ANOVA) for the independent input variables in order to find which parameter significantly affects the desired response, then, (5) determine the situation of the quadratic model of RSM and decide whether the model of RSM needs screening variables or not and finally, (6) optimize and conduct confirmation experiment and verify the predicted performance characteristics.

In the current study, the relationship between the cutting conditions and the technology parameters aspect is given as:

$$
Y=\phi(V c, f, a p),
$$

where $Y$ is the desired machinability aspect and $\phi$ is the response function. The approximation of $Y$ is proposed by using a nonlinear (quadratic) mathematical model, which is suitable for studying the interaction effects of process parameters on machinability characteristics. In the present work, the RMS-based second order mathematical model is given by

$$
Y=b_{0}+\sum_{i=1}^{k} b_{i} X_{i}+\sum_{i, j}^{k} b_{i j} X_{i} X_{j}+\sum_{i=1}^{k} b_{i i} X_{i}^{2},
$$

where $b_{0}$ is the free term of the regression equation, the coefficients, $b_{1}, b_{2}, \ldots b_{k}$ and $b_{11}, b_{22}, \ldots b_{k k}$ are the linear and the quadratic terms respectively; while $b_{12}, b_{13}, \ldots b_{k-1}$ are the interacting terms. The experimental plan is developed to assess the influence of cutting speed $\left(V_{c}\right)$, feed rate $(f)$ and depth of cut $(a p)$ on the surface roughness parameters $(R a, R t$ and $R z)$ and cutting force components $(F a, F r$ and $F v)$. Three levels are defined for each cutting variable as given in table 3 . The variable levels are chosen within the intervals recommended by cutting tool manufacturer. Three cutting variables at three levels led to a total of 27 tests.

\section{Results and discussion}

The plan of tests was developed with the aim of relating the influence of cutting speed $(V c)$, feed rate $(f)$ and depth of cut $(a p)$, with the surface roughness parameters and cutting force components.

Table 4 shows all values of surface roughness and cutting forces. The surface roughness was obtained in the range of $0.22-0.80,2.00-5.60$ and $0.50-3.40 \mu \mathrm{m}$ for $R a, R t$ and $R z$, respectively. The feed force $(F a)$, thrust force $(F r)$ and cutting force $(F v)$ were obtained in range of 20.49150.64 N, 43.28-396.67 N and 38.5-393.70 N, respectively. Furthermore, thrust force is about $\sim 1.12$ higher than cutting force. König et al (1984) reported that thrust force is about twice that 
Table 4. Experimental results for surface roughness parameters and cutting force components.

\begin{tabular}{|c|c|c|c|c|c|c|c|c|c|}
\hline \multirow{2}{*}{$\begin{array}{l}\text { Test } \\
\text { number }\end{array}$} & \multicolumn{3}{|c|}{ Factors } & \multicolumn{3}{|c|}{ Cutting force components } & \multicolumn{3}{|c|}{ Surface roughness parameters } \\
\hline & $a p, \mathrm{~mm}$ & $f, \mathrm{~mm} / \mathrm{rev}$ & $V c, \mathrm{~m} / \mathrm{min}$ & $F a, \mathrm{~N}$ & $F r, \mathrm{~N}$ & $F v, \mathrm{~N}$ & $R a, \mu \mathrm{m}$ & $R t, \mu \mathrm{m}$ & $R z, \mu \mathrm{m}$ \\
\hline 1 & 0.45 & 0.16 & 180 & 143.62 & 329.03 & 305 & 0.59 & 4.2 & 2.28 \\
\hline 2 & 0.15 & 0.16 & 180 & 54.10 & 111.89 & 87.86 & 0.58 & 4.2 & 2.1 \\
\hline 3 & 0.45 & 0.16 & 120 & 143.03 & 396.67 & 393.70 & 0.76 & 5.1 & 3.4 \\
\hline 4 & 0.30 & 0.12 & 240 & 57.44 & 113.83 & 89.78 & 0.42 & 3.2 & 1.33 \\
\hline 5 & 0.30 & 0.12 & 180 & 64.54 & 111.46 & 87.42 & 0.48 & 3.5 & 1.73 \\
\hline 6 & 0.30 & 0.08 & 120 & 70.09 & 195.07 & 171.03 & 0.41 & 3.1 & 1.80 \\
\hline 7 & 0.30 & 0.08 & 240 & 50.56 & 122.17 & 98.13 & 0.24 & 2.1 & 0.60 \\
\hline 8 & 0.15 & 0.16 & 240 & 48.62 & 74.56 & 50.53 & 0.48 & 3.6 & 1.57 \\
\hline 9 & 0.15 & 0.12 & 240 & 26.26 & 43.28 & 38.5 & 0.39 & 3.0 & 1.27 \\
\hline 10 & 0.15 & 0.08 & 180 & 31.54 & 102.29 & 78.26 & 0.27 & 2.3 & 0.50 \\
\hline 11 & 0.30 & 0.12 & 120 & 72.52 & 211.19 & 188.55 & 0.68 & 4.8 & 2.43 \\
\hline 12 & 0.30 & 0.16 & 120 & 104.43 & 262.63 & 238.59 & 0.79 & 5.4 & 3.0 \\
\hline 13 & 0.45 & 0.12 & 180 & 87.82 & 232.60 & 208.57 & 0.46 & 3.3 & 1.80 \\
\hline 14 & 0.45 & 0.12 & 240 & 112.06 & 210.01 & 185.95 & 0.42 & 3.1 & 1.40 \\
\hline 15 & 0.15 & 0.16 & 120 & 82.44 & 164.88 & 140.85 & 0.80 & 5.6 & 3.03 \\
\hline 16 & 0.45 & 0.08 & 180 & 82.58 & 224.15 & 200.12 & 0.28 & 2.2 & 1.07 \\
\hline 17 & 0.45 & 0.08 & 120 & 85.44 & 291.44 & 267.41 & 0.38 & 3.2 & 2.0 \\
\hline 18 & 0.30 & 0.16 & 180 & 109.21 & 180.74 & 156.7 & 0.59 & 4.2 & 2.16 \\
\hline 19 & 0.15 & 0.08 & 240 & 20.49 & 89.98 & 65.95 & 0.22 & 2.0 & 0.60 \\
\hline 20 & 0.15 & 0.08 & 120 & 50.39 & 121.45 & 97.42 & 0.40 & 3.0 & 1.70 \\
\hline 21 & 0.45 & 0.16 & 240 & 150.64 & 339.77 & 315.74 & 0.49 & 3.5 & 1.70 \\
\hline 22 & 0.15 & 0.12 & 180 & 35.72 & 60.12 & 40.26 & 0.44 & 3.4 & 1.63 \\
\hline 23 & 0.30 & 0.08 & 180 & 56.38 & 104.51 & 80.47 & 0.28 & 2.4 & 0.86 \\
\hline 24 & 0.30 & 0.16 & 240 & 86.94 & 134.09 & 110.04 & 0.51 & 3.7 & 1.60 \\
\hline 25 & 0.15 & 0.12 & 120 & 52.81 & 147.68 & 123.65 & 0.66 & 5.0 & 2.50 \\
\hline 26 & 0.45 & 0.12 & 120 & 110.71 & 313.73 & 289.7 & 0.69 & 4.6 & 2.80 \\
\hline 27 & 0.45 & 0.08 & 240 & 105.1 & 186.71 & 162.68 & 0.24 & 2.0 & 0.73 \\
\hline
\end{tabular}

of cutting force in hard turning. The thrust force is larger than cutting force in hard turning is also reported by Fnides et al (2008).

\subsection{Graphic analysis}

Figure 1 expresses the evolution of surface roughness criteria versus cutting speed, for several feed rates. According to the graph, it can be seen that the surface roughness increase with increase feed rates, because its increase generates helicoid furrows the result tool shape helicoid movement tool-workpiece. These furrows are deeper and broader as the feed rate increases (Fnides et al 2008). For this reason, weak feed rate have to be employed during turning operation. Similar results were reported by Bouacha et al (2010) when turning AISI 52100 steel (64 $\mathrm{HRC})$ using $\mathrm{CBN}$ tool. The interactions $(V c \times a p),(a p \times H),(f \times f)$ and the cutting speed $(V c)$ do not show a significant contribution on the surface roughness evolution. The best surface roughness was achieved at the lowest feed rate and highest cutting speed.

In figure 2 the evolution of cutting forces with the cutting speed for different feed rate can be seen. From figure 2, it can be realized that the cutting forces decrease with increase cutting speed. This figure shows that lower cutting speed and the higher feed rate resulted in higher 


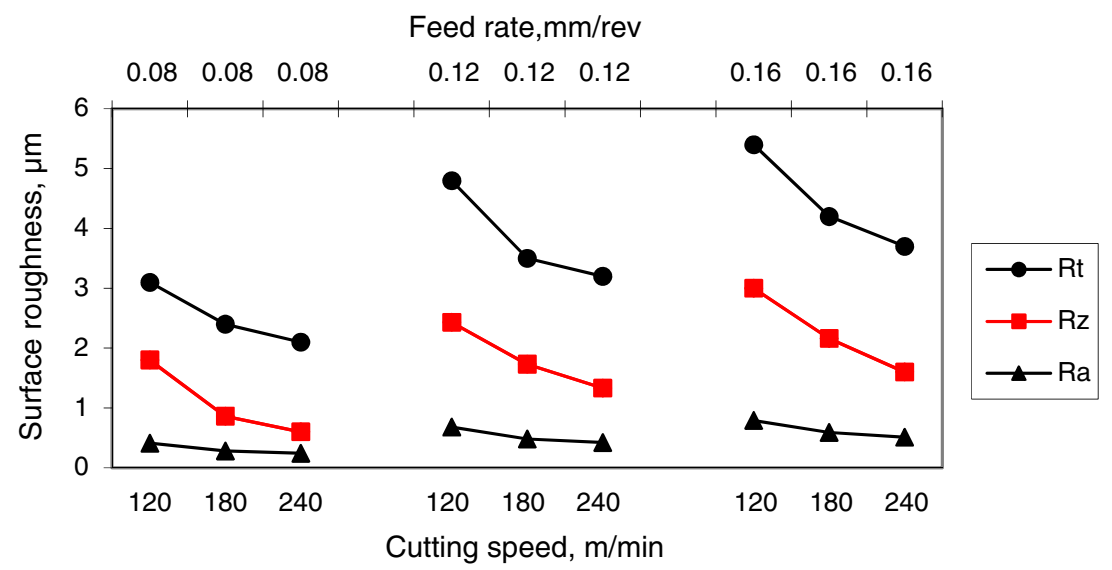

Figure 1. Effect of cutting speed on surface roughness at various feed rates.

cutting forces. Similar results were obtained by Lalwani et al (2008) when turning MDN250 steel (50 HRC) using coated ceramic tool.

\subsection{ANOVA and effects of factors}

The ANOVA of the data with the surface roughness parameters and cutting force components, with the objective of analysing the influence of cutting speed $(V c)$, feed rate $(f)$ and depth of cut $(a p)$ on the total variance of the results were carried out.

The table of ANOVA shows the degrees of freedom (DF), sum of squares (SC), mean squares (MS), F-values (F) and probability (P) in addition to the percentage contribution (Cont. \%) of each factor and different interactions. A low P-value $(\leq 0.05)$ indicates statistical significance for the source on the corresponding response (i.e., $\alpha=0.05$, or $95 \%$ confidence level), this indicates that the obtained models are considered to be statistically significant, which is desirable; as it demonstrates that the terms in the model have a significant effect on the response.

The other important coefficient, $R^{2}$, which is called coefficient of determination in the resulting ANOVA tables, is defined as the ratio of the explained variation to the total variation and is a

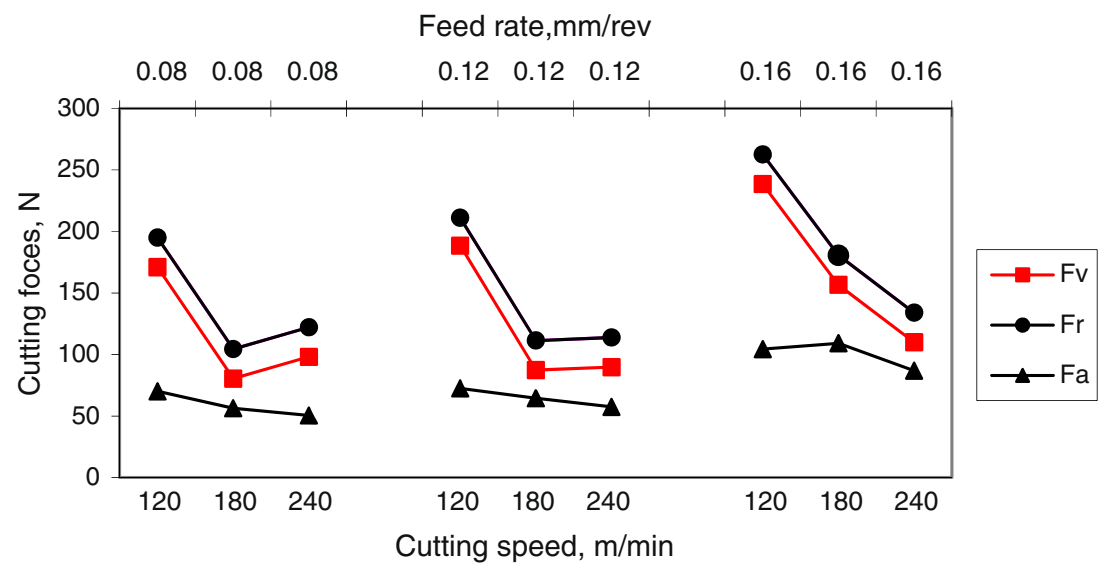

Figure 2. Effect of cutting speed on cutting forces at various feed rates. 
Table 5. Analysis of variance (ANOVA) for $R a$.

\begin{tabular}{lrlccrrl}
\hline Term. & DF & \multicolumn{1}{c}{ SC } & \multicolumn{1}{c}{ MS } & F & P & Cont.\% & Remarks \\
\hline$a p$ & 1 & 0.00027222 & 0.00027222 & 0.8228515 & 0.3770 & 0.04 & Not significant \\
$f$ & 1 & 0.45760556 & 0.45760556 & 1383.21337 & $<0.0001$ & 59.11 & Significant \\
$V c$ & 1 & 0.2592 & 0.2592 & 783.488969 & $<0.0001$ & 33.48 & Significant \\
$a p \times f$ & 1 & $7.5 \mathrm{E}-05$ & $7.5 \mathrm{E}-05$ & 0.22670398 & 0.6400 & 0.01 & Not significant \\
$a p \times V c$ & 1 & 0.000675 & 0.000675 & 2.04033586 & 0.1713 & 0.09 & Not significant \\
$V c \times f$ & 1 & 0.01203333 & 0.01203333 & 36.3733948 & $<0.0001$ & 1.55 & Significant \\
$a p \times a p$ & 1 & 0.00115741 & 0.00115741 & 3.49851827 & 0.0787 & 0.15 & Not significant \\
$f \times f$ & 1 & 0.01742407 & 0.01742407 & 52.6680935 & $<0.0001$ & 2.25 & Significant \\
$V c \times V c$ & 1 & 0.02002963 & 0.02002963 & 60.5439579 & $<0.0001$ & 2.59 & Significant \\
Error & 17 & 0.00562407 & 0.00033083 & & & 0.73 & \\
Total & 26 & 0.7740963 & & & & & \\
\hline
\end{tabular}

measure of the fit degree. When $R^{2}$ approaches to unity, it indicates a good correlation between the experimental and the predicted values.

3.2a ANAOVA for surface roughness: The characterization of the machined surface quality was limited to the criteria of total roughness $(R t)$, arithmetic mean roughness $(R a)$ and mean depth of roughness $(R z)$.

Arithmetic mean roughness $(\mathrm{Ra})$ : Table 5 shows that the main effects of the cutting speed, feed rate and the products cutting speed/cutting speed, feed rate/feed rate and cutting speed/feed rate are significant with respect to arithmetic mean roughness $(R a)$, the depth of cut factor and the interaction depth of cut/depth of cut, cutting speed/depth of cut, feed rate/depth of cut do not present a statistical significance on the arithmetic mean roughness $(R a)$. However, a qualitative comparison can be made. For example, (Feng 2001) found that the depth of cut does not impact on the surface roughness of turned surfaces. However, feed rate, nose radius, work material and speeds, the tool point angle have a significant impact on the observed surface roughness using the fractional factorial experimentation approach (El Baradie 1997). $R a$ model is given by equation (3). Its coefficient of correlation $R^{2}$ is $98.13 \%$.

Table 6. Analysis of variance for $R t$.

\begin{tabular}{lrcccrrl}
\hline Term. & DF & SC & MS & F & P & Cont.\% & Remarks \\
\hline$a p$ & 1 & 0.045 & 0.045 & 2.34382979 & 0.1442 & 0.15 & Not significant \\
$f$ & 1 & 16.4355556 & 16.4355556 & 856.04766 & $<0.0001$ & 56.58 & Significant \\
$V c$ & 1 & 10.2755556 & 10.2755556 & 535.203404 & $<0.0001$ & 35.38 & Significant \\
$a p \times f$ & 1 & 0.04083333 & 0.04083333 & 2.12680851 & 0.1630 & 0.14 & Not significant \\
$a p \times V c$ & 1 & 0.04083333 & 0.04083333 & 2.12680851 & 0.1630 & 0.14 & Not significant \\
$V c \times f$ & 1 & 0.3675 & 0.3675 & 19.1412766 & 0.0004 & 1.27 & Significant \\
$a p \times a p$ & 1 & 0.04166667 & 0.04166667 & 2.17021277 & 0.1590 & 0.14 & Not significant \\
$f \times f$ & 1 & 0.66666667 & 0.66666667 & 34.7234043 & $<0.0001$ & 2.30 & Significant \\
$V c \times V c$ & 1 & 0.80666667 & 0.80666667 & 42.0153191 & $<0.0001$ & 2.78 & Significant \\
Error & 17 & 0.32638889 & 0.01919935 & & & 1.12 & \\
Total & 26 & 29.0466667 & & & & & \\
\hline
\end{tabular}


Table 7. Analysis of variance for $R z$.

\begin{tabular}{lccccccl}
\hline Term. & DF & SC & MS & F & P & Cont. $\%$ & Remarks \\
\hline$a p$ & 1 & 0.2888 & 0.2888 & 27.9857073 & $<0.0001$ & 1.83 & Significant \\
$f$ & 1 & 6.6978 & 6.6978 & 649.039717 & $<0.0001$ & 42.41 & Significant \\
$V c$ & 1 & 7.81442222 & 7.81442222 & 757.244227 & $<0.0001$ & 49.48 & Significant \\
$a p \times f$ & 1 & 0.00853333 & 0.00853333 & 0.82690917 & 0.3759 & 0.054 & Not significant \\
$a p \times V c$ & 1 & 0.02803333 & 0.02803333 & 2.71652583 & 0.1177 & 0.177 & Not significant \\
$V c \times f$ & 1 & 0.081675 & 0.081675 & 7.91458671 & 0.0120 & 0.517 & Significant \\
$a p \times a p$ & 1 & 0.02080741 & 0.02080741 & 2.01630891 & 0.1737 & 0.132 & Not significant \\
$f \times f$ & 1 & 0.17567407 & 0.17567407 & 17.0234183 & 0.0007 & 1.112 & Significant \\
$V c \times V c$ & 1 & 0.50074074 & 0.50074074 & 48.5234896 & $<0.0001$ & 3.171 & Significant \\
Error & 17 & 0.17543241 & 0.01031955 & & & 1.112 & \\
Total & 26 & 15.7919185 & & & & & \\
\hline
\end{tabular}

Total roughness $(R t)$ : From the analysis of table 6 , it can be seen that the feed rate factor $($ Cont. $\approx 56.58 \%)$ and cutting speed (Cont. $\approx 35.38 \%$ ) have statistical significance on the total roughness $(R t)$. The depth of cut and interactions depth of cut/depth of cut, feed rate/depth of cut do not present a statistical significance on the total roughness $(R t) . R t$ model is given by equation (4). Its coefficient of correlation $R^{2}$ is $97 \%$.

Mean depth of roughness $(R z)$ : Finality, from table 7, it can be realized that the cutting speed factor (Cont. $\approx 49.48 \%$ ) and the feed rate factor (Cont. $\approx 42.41 \%$ ) are noticed. The depth of cut and interaction feed rate/depth of cut do not present a statistical significance on the mean depth of roughness $(R z) . R z$ model is given by equation (5) and its coefficient of correlation $R^{2}$ is $97.22 \%$.

3.2b ANOVA for cutting force: The ANOVA of the data with cutting force components, with an objective of analysing the influences of cutting speed, of feed and depth of cut on the total variance of results.

Feed force $(\mathrm{Fa})$ : From table 8, we can observe that the depth of cut (Cont. $\approx 63.67 \%)$ and feed rate (Cont. $\approx 22.83 \%$ ) have great influence on the feed force $(F a)$ obtained, especially the depth

Table 8. Analysis of variance for $F a$.

\begin{tabular}{lrcccrrl}
\hline Term. & DF & SC & MS & F & P & Cont. \% & Remarks \\
\hline$a p$ & 1 & 21261.2821 & 21261.2821 & 504.184441 & $<0.0001$ & 63.67 & Significant \\
$f$ & 1 & 7624.47842 & 7624.47842 & 180.804873 & $<0.0001$ & 22.83 & Significant \\
$V c$ & 1 & 718.836806 & 718.836806 & 17.0463066 & 0.0007 & 2.15 & Significant \\
$a p \times f$ & 1 & 552.570408 & 552.570408 & 13.1035091 & 0.0021 & 1.65 & Significant \\
$a p \times V c$ & 1 & 1177.90268 & 1177.90268 & 27.9324737 & $<0.0001$ & 3.53 & Significant \\
$V c \times f$ & 1 & 16.1704083 & 16.1704083 & 0.3834608 & 0.5440 & 0.05 & Not significant \\
$a p \times a p$ & 1 & 116.01338 & 116.01338 & 2.75111072 & 0.1155 & 0.35 & Not significant \\
$f \times f$ & 1 & 1030.00936 & 1030.00936 & 24.4253707 & 0.0001 & 3.08 & Significant \\
$V c \times V c$ & 1 & 181.316713 & 181.316713 & 4.29969676 & 0.0536 & 0.54 & Significant \\
Error & 17 & 716.884071 & 42.1696513 & & & 2.15 & \\
Total & 26 & 33395.4643 & & & & 100 & \\
\hline
\end{tabular}


Table 9. Analysis of variance for $F r$.

\begin{tabular}{lrcccccl}
\hline Term. & DF & SC & MS & F & P & Cont. $\%$ & Remarks \\
\hline$a p$ & 1 & 143114.283 & 143114.283 & 438.261478 & $<0.0001$ & 63.53 & Significant \\
$f$ & 1 & 17021.355 & 17021.3550 & 52.1248057 & $<0.0001$ & 7.55 & Significant \\
$V c$ & 1 & 34441.7509 & 34441.7509 & 105.471602 & $<0.0001$ & 15.29 & Significant \\
$a p \times f$ & 1 & 8672.02568 & 8672.02568 & 26.5565023 & $<0.0001$ & 3.85 & Significant \\
$a p \times V c$ & 1 & 109.143008 & 109.143008 & 0.33423062 & 0.5708 & 0.048 & Not significant \\
$V c \times f$ & 1 & 338.034675 & 338.034675 & 1.03516975 & 0.3232 & 0.15 & Not significant \\
$a p \times a p$ & 1 & 5930.21282 & 5930.21282 & 18.1601988 & 0.0005 & 2.63 & Significant \\
$f \times f$ & 1 & 5425.2294 & 5425.2294 & 16.6137789 & 0.0008 & 2.40 & Significant \\
$V c \times V c$ & 1 & 4677.71682 & 4677.71682 & 14.3246575 & 0.0015 & 2.08 & Significant \\
Error & 17 & 5551.34991 & 326.549995 & & & 2.47 & \\
Total & 26 & 225281.102 & & & & 100 & \\
\hline
\end{tabular}

of cut factor. The interactions feed rate/feed rate (Cont. $\approx 3.08 \%)$, cutting speed/depth of cut (Cont. $\approx 3.53 \%)$ and feed rate/depth of cut (Cont. $\approx 1.65 \%)$ present significant parameters.Fa model is given by equation (6). Its coefficient of correlation $R^{2}$ is $95.16 \%$.

Thrust force $(F r)$ : From table 9, it can be apparently shown that the most significant factor on the thrust force is depth of cut, which explains $63.53 \%$ contribution of total variation. The next largest contribution is cutting speed with the contribution of 15.29. The interactions cutting speed/cutting speed (Cont. $\approx 2.08 \%$ ), feed rate/feed rate (Cont. $\approx 2.41 \%$ ) depth of cut/depth of cut (Cont. $\approx 2.63 \%)$ and feed rate/depth of cut (Cont. $\approx 3.85 \%$ ) present percentages of significance of contribution on the specific thrust force $(F r)$. This indicates that feed rate has little influence on thrust force and it agrees with the results of Özel et al (2005). Fr model is given by equation (7). Its coefficient of correlation $R^{2}$ is $92.22 \%$.

Tangential force $(F v)$ : Equally, from table 10 we can be observe the depth of cut factor $($ Cont. $\approx 62.06 \%)$, the cutting speed factor $($ Cont. $\approx 15.22 \%)$ and feed rate factor (Cont. $\approx$ $8.08 \%$ ). The interactions cutting speed/cutting speed (Cont. $\approx 2.35 \%$ ), feed rate/feed rate (Cont. $\approx 2.15 \%)$, depth of cut/depth of cut (Cont. $\approx 3.01 \%$ ), and feed rate/depth of cut $($ Cont. $\approx 4.4 \%)$ have great influence on the cutting force $(F v)$, especially the depth of cut. The

Table 10. Analysis of variance for $F v$.

\begin{tabular}{lrrrcrrl}
\hline Term. & DF & \multicolumn{1}{c}{ SC } & \multicolumn{1}{c}{ MS } & F & P & Cont.\% & Remarks \\
\hline$a p$ & 1 & 143748.071 & 143748.071 & 482.240158 & $<0.0001$ & 62.06 & Significant \\
$f$ & 1 & 18721.770 & 18721.770 & 62.8070295 & $<0.0001$ & 8.08 & Significant \\
$V c$ & 1 & 35251.320 & 35251.320 & 118.25969 & $<0.0001$ & 15.22 & Significant \\
$a p \times f$ & 1 & 10184.430 & 10184.430 & 34.1663121 & $<0.0001$ & 4.40 & Significant \\
$a p \times V c$ & 1 & 566.775 & 566.775 & 1.90139388 & 0.1858 & 0.24 & Not significant \\
$V c \times f$ & 1 & 685.540 & 685.540 & 2.29982439 & 0.1478 & 0.30 & Not significant \\
$a p \times a p$ & 1 & 6974.586 & 6974.586 & 23.3980591 & 0.0002 & 3.01 & Significant \\
$f \times f$ & 1 & 4982.209 & 4982.209 & 16.7141132 & 0.0008 & 2.15 & Significant \\
$V c \times V c$ & 1 & 5437.063 & 5437.06338 & 18.2400382 & 0.0005 & 2.35 & Significant \\
Error & 17 & 5067.427 & 298.083991 & & & 2.19 & \\
Total & 26 & 231619.195 & & & & 100 & \\
\hline
\end{tabular}


interactions cutting speed/feed rate and cutting speed/depth of cut do not present percentages of significance of contribution on the tangential force obtained. $F v$ model is given by equation (6). Its coefficient of correlation $R^{2}$ is $86.40 \%$. $F v$ model is given by equation (8). Its coefficient of correlation $R^{2}$ is $93.26 \%$.

It should be noticed that the error associated with the ANOVA tables has $0.73,1.12$ and $1.112 \%$ for surface roughness parameters $R a, R t$ and $R z$, respectively, 2.15, 2.47 and $2.19 \%$ for cutting force components $\mathrm{Fa}, \mathrm{Fr}$ and $\mathrm{Fv} \%$, respectively.

\subsection{Regression equations}

The relationship between the factors and the performance measures were modelled by quadratic regression. The regression equations obtained were as follows:

$$
\begin{aligned}
R a= & 0.08463+0.963 a p+14.56 f-6.44 \times 10^{-3} V c \\
& -0.41667 a p \times f+8.33 \times 10^{-3} a p \times V c \\
& -0.01319 f \times V c-0.617 a p^{2}-33.68 f^{2}+1.6049 \times 10^{-4} V c^{2} \\
R t= & 1.46944+1.888 a p+89.93 f-0.04255 \times 10^{-3} V c-9.722 a p \\
& \times f+6.481 \times 10^{-3} a p \times V c \\
& -0.0729 f \times V c-3.703 a p^{2}-208.33 f^{2}+1.0185 \times 10^{-4} V c^{2} \\
R z= & 1.6412+0.77 a p+48.43 f-0.03413 V c-4.44 a p \\
& \times f-5.37 \times 10^{-3} a p \times V c \\
& -0.00343 f \times V c-2.617 a p^{2}-106.94 f^{2}+8.024 \times 10^{-5} V c^{2} \\
F a= & 222.45-222 a p-1703.03 f-0.93 V c+1130.97 a p \times f-1.1 a p \times V c \\
& -0.48368 f \times V c+195.43 a p^{2}+8188.88 f^{2}+1.52 \times 10^{-3} V c^{2} \\
F r= & 724.61-721.24 a p-4687.78 f-3.155 V c+4480.41 a p \\
& \times f-0.335 a p \times V c \\
& -2.211 f \times V c+1397.25 a p^{2}+18793.75 f^{2}+7.75 \times 10^{-3} V c^{2}
\end{aligned}
$$

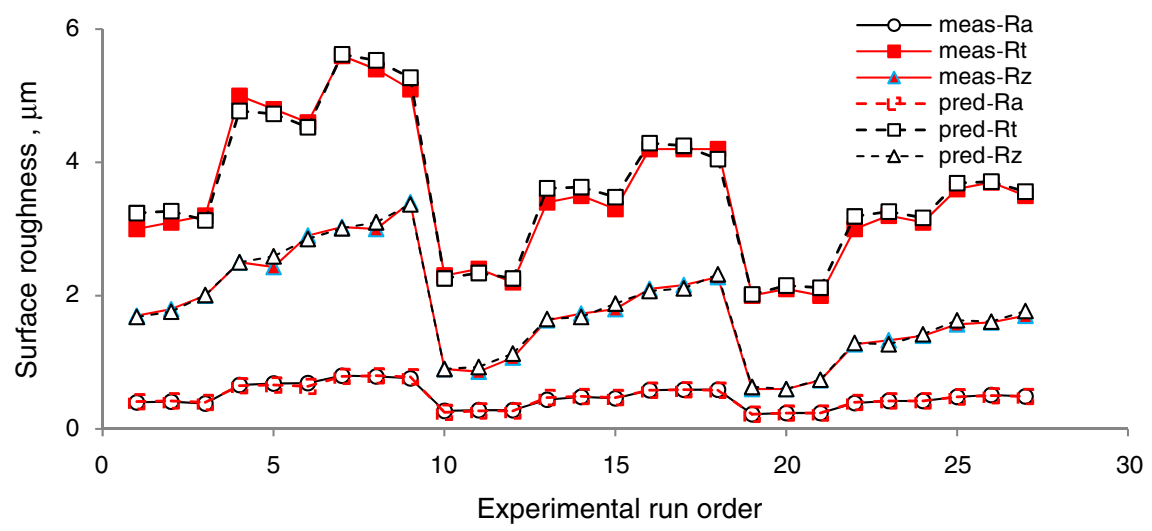

Figure 3. Comparison between measured and predicted values for surface roughness. 


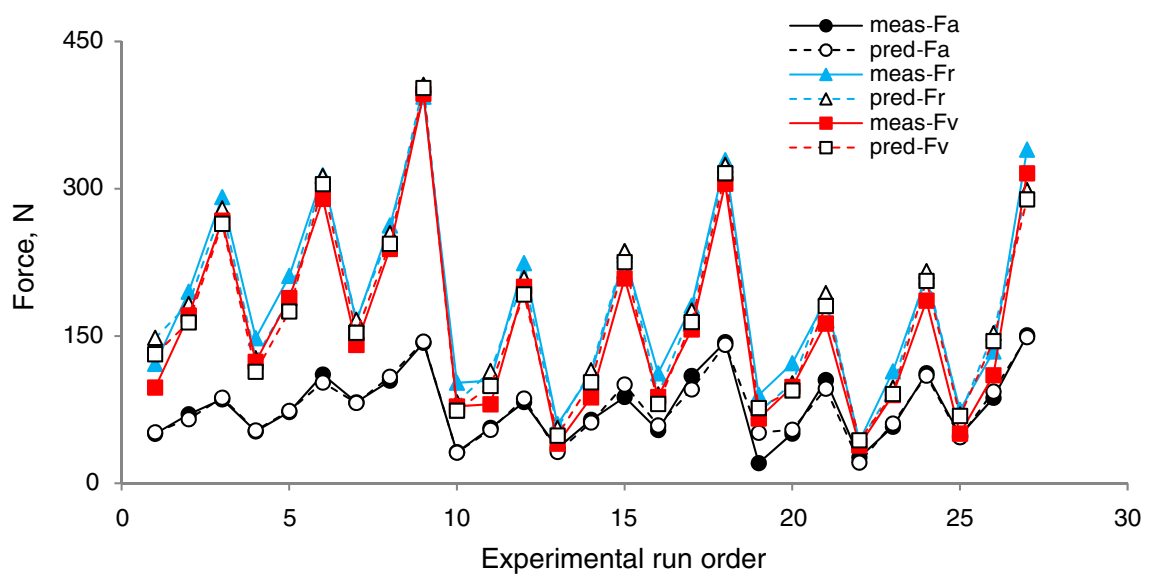

Figure 4. Comparison between measured and predicted values for cutting forces.

$$
\begin{aligned}
F v= & 685.81-758.62 a p-4405.9 f-3.14 V c+4855.41 a p \times f-0.7631 a p \times V c \\
& -3.149 f \times V c+1515.3 a p^{2}+18010.06 f^{2}+8.36 \times 10^{-3} V c^{2}
\end{aligned}
$$

These equations give the expected value of surface roughness parameters and cutting force components for any combination of factor levels given that the levels are within the ranges given in table 4. The above mathematical model can be used to predict the values of the surface roughness parameters and cutting force components the limits of the factors studied. The differences between the measured and predicted response are illustrated in figures 3 and 4 . The results of comparison were proven to predict the values of surface roughness parameters and cutting force components close to those readings recorded experimentally with a $95 \%$ confidence interval. Good agreement is observed between these values as seen in figures 5 and 6 .

\subsection{Responses surface analysis}

Figure 7a presents the influence of cutting speed $(V c)$, feed rate $(f)$ and depth of cut $(a p)$ on arithmetic mean roughness $(R a)$, The effects of the cutting speed $(V c)$, feed rate $(f)$ and depth of cut $(a p)$ on total roughness $(R t)$ are shown in figure $7 \mathrm{~b}$. The estimated surface response (mean
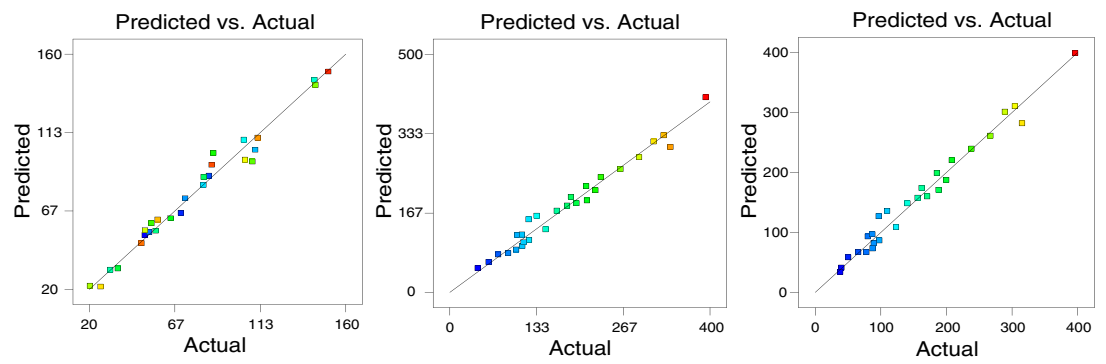

Figure 5. Comparison of measured and predicted value for $(F a, F r$ and $F v)$. 

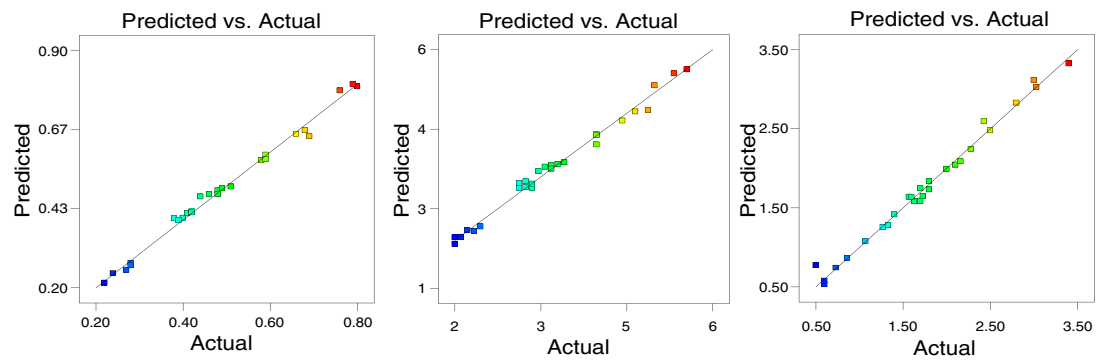

Figure 6. Comparison of measured and predicted value for $(R a, R t$ and $R z)$.

depth of roughness, $R z$ ) in relation to the cutting speed $(V c)$, feed rate $(f)$ and depth of cut (ap) are shown in figure $7 \mathrm{c}$.

The estimated cutting force components, namely, the feed force, thrust force and cutting force in relation to cutting conditions are given in figures $8 \mathrm{a}$ to $\mathrm{c}$. As seen from these figures, the cutting forces components increase with the increase in depth of cut and decrease with the increase cutting speed.
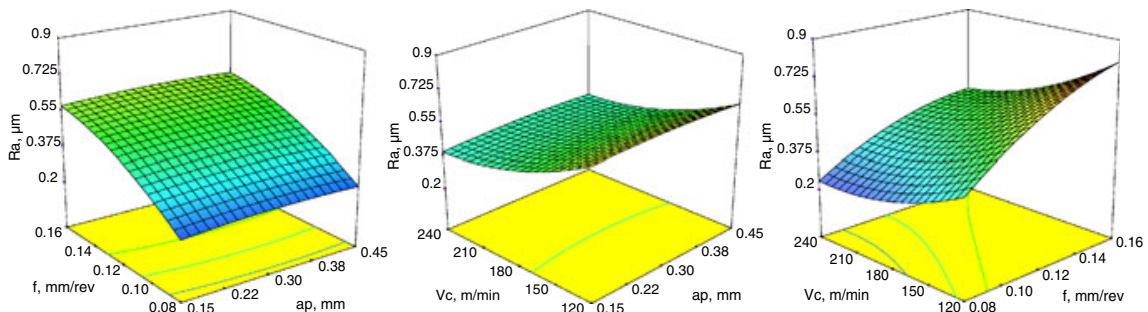

(a)
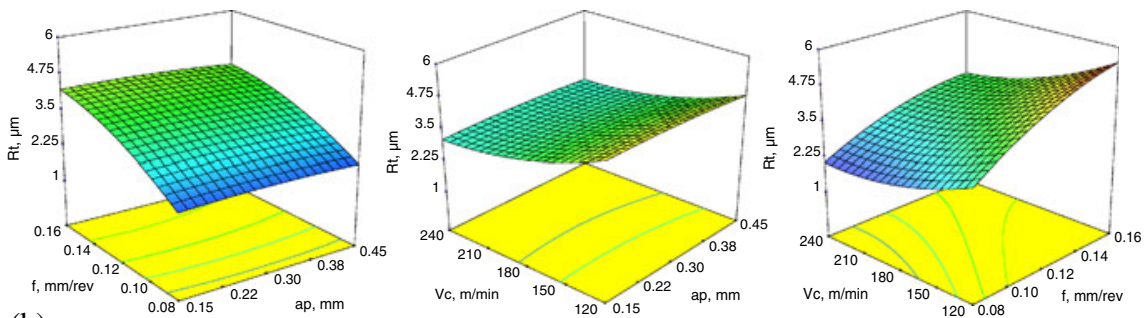

(b)
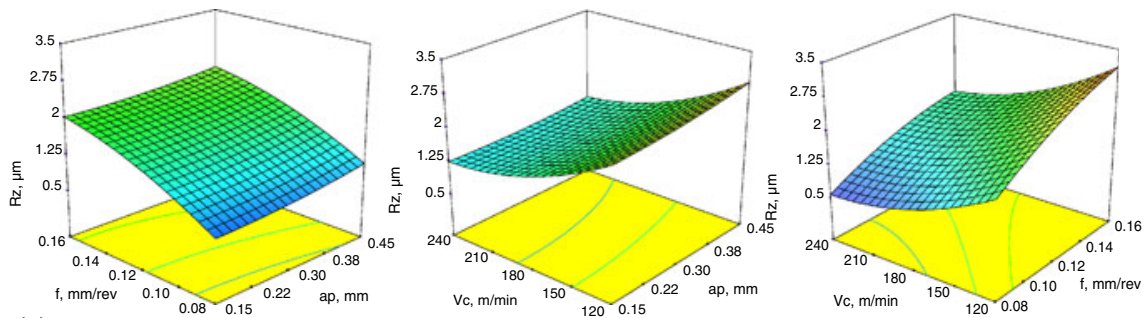

(c)

Figure 7. Estimated responses surface of surface roughness parameters versus $V c, f$ and $a p$. 

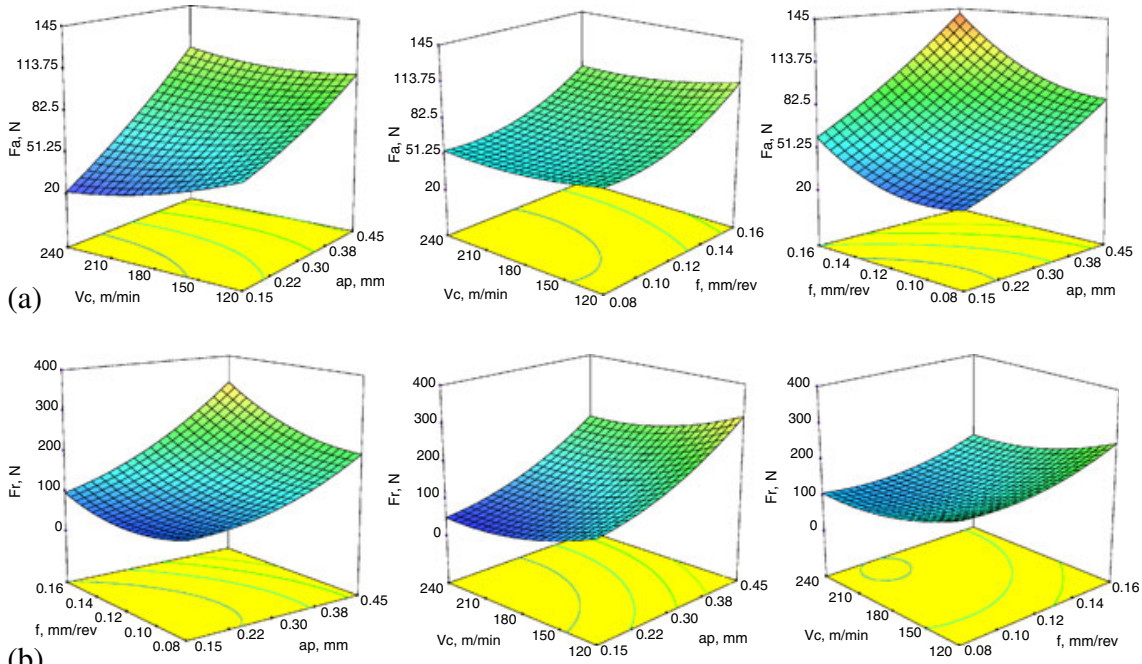

(b)
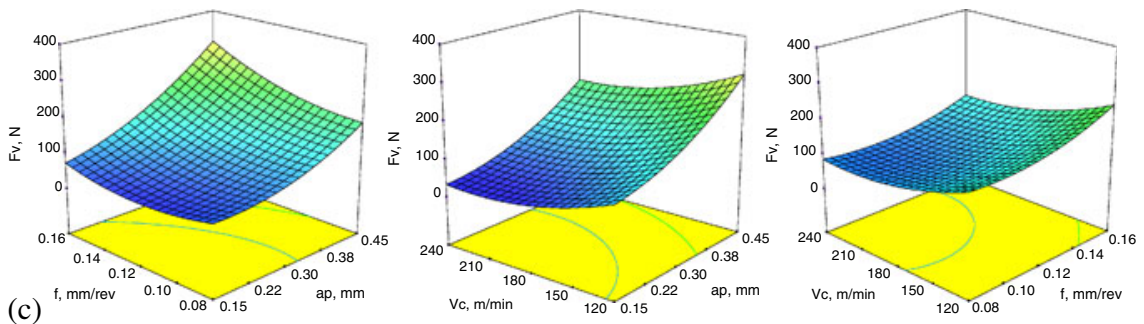

Figure 8. Estimated responses surface of cutting force components versus $V c, f$ and $a p$.

\section{Optimization of cutting conditions}

The optimal manufacturing conditions for machining hot work steel (X38CrMoV5-1) with the constraints of cutting parametric range is to find the optimal value of cutting parameters in order to minimize the values of the surface roughness parameters ( $R a, R t$ and $R z)$ and cutting force components ( $F a, F r$ and $F v$ ) during the hard turning process. The constraints used during the

Table 11. Constraints for optimization of cutting conditions.

\begin{tabular}{lccc}
\hline Condition & Goal & Lower limit & Upper limit \\
\hline Cutting speed, $V c$ & Is in range & 120 & 240 \\
Feed rate, $f$ & Is in range & 0.08 & 0.16 \\
Depth of cut, $a p$ & Is in range & 0.15 & 0.45 \\
$R a(\mu \mathrm{m})$ & Minimize & 0.22 & 0.8 \\
$R t(\mu \mathrm{m})$ & Minimize & 2 & 5.6 \\
$R z(\mu \mathrm{m})$ & Minimize & 0.5 & 3.4 \\
$F a(\mathrm{~N})$ & Minimize & 20.49 & 150.64 \\
$F r(\mathrm{~N})$ & Minimize & 43.28 & 393.7 \\
$F v(\mathrm{~N})$ & Minimize & 38.5 & 396.67 \\
\hline
\end{tabular}


Table 12. Response optimization for surface parameters and cutting force components.

\begin{tabular}{lcccccccccc}
\hline & & \multicolumn{3}{c}{ Optimum combination } & & \multicolumn{4}{c}{ Predicted } \\
\cline { 3 - 8 } Parameters & \multirow{2}{*}{ Goal } & $V c, \mathrm{~m} / \mathrm{min}$ & $f, \mathrm{~mm} / \mathrm{rev}$ & $a p, \mathrm{~mm}$ & Lower & Target & Upper & response & Desirability \\
\hline$R a(\mu \mathrm{m})$ & Minimum & 227.48 & 0.08 & 0.15 & 0.22 & 0.22 & 0.8 & 0.219 & 1 \\
$R t(\mu \mathrm{m})$ & Minimum & 227.48 & 0.08 & 0.15 & 2 & 2 & 5.6 & 1.965 & 1 \\
$R z(\mu \mathrm{m})$ & Minimum & 227.48 & 0.08 & 0.15 & 0.5 & 0.50 & 3.4 & 0.558 & 1 \\
$F a(\mathrm{~N})$ & Minimum & 227.48 & 0.08 & 0.15 & 20.49 & 20.49 & 150.64 & 22.76 & 0.997 \\
$F r(\mathrm{~N})$ & Minimum & 227.48 & 0.08 & 0.15 & 43.28 & 43.28 & 393.70 & 77.08 & 0.975 \\
$F v(\mathrm{~N})$ & Minimum & 227.48 & 0.08 & 0.15 & 38.50 & 38.50 & 396.67 & 60.32 & 0.985 \\
\hline
\end{tabular}

optimization process are summarized in table 11 . The optimal solutions are reported in table 12 in order of decreasing desirability level.

Table 12 shows the RSM optimization results for the surface roughness parameters and cutting force components. The optimum cutting parameters obtained in table 8 are found to be cutting speed of $227.48 \mathrm{~m} / \mathrm{min}$, feed rate of $0.08 \mathrm{~mm} / \mathrm{rev}$ and depth of cut $0.15 \mathrm{~mm}$. The optimized surface roughness parameters are $R a=0.219 \mu \mathrm{m}, R t=1.965 \mu \mathrm{m}$ and $R z=0.558 \mu \mathrm{m}$. In addition, the optimized cutting force components are $F a=22.76 \mathrm{~N}, F r=77.08 \mathrm{~N}$ and $F v=$ $60.32 \mathrm{~N}$.

\section{Conclusion}

In this study, a detailed experimental investigation is presented for the effects of cutting speed, feed rate and depth of cut on the cutting force components and the surface roughness parameters in hard turning of X38CrMoV5-1 (50 HRC) steel with CBN tool. A three-factor, three-level factor technique can be employed easily to develop a mathematical model for predicting surface roughness parameters and cutting force components of cutting conditions during the turning operation.

The results have indicated that the effect of depth of cut on the cutting force components is remarkably significant. According to presented results, the surface roughness is highly affected by feed rate, whereas the cutting speed has negative effect and depth of cut a negligible influence.

The optimum machining conditions combinations for minimizing surface roughness parameters and cutting force components for hard turning of the $\mathrm{X} 38 \mathrm{CrMoV} 5-1$ within the ranges of variable studied are also tested through confirmation experiments that show fairly good agreement with prediction of empirical models developed. However, the validity of the procedure is limited to the range of factors considered for the experimentation.

\section{Acknowledgements}

The authors would like to thank the Algerian Ministry of Higher Education and Scientific Research (MESRS) and the Delegated Ministry for Scientific Research (MDRS) for granting financial support for CNEPRU Research Project - LMS : $\mathrm{n}^{\circ}$ : 0301520090008 (University 08 May 1945 Guelma). 


\section{Nomenclature}

ap Depth of cut, mm.

$f \quad$ Feed rate, $\mathrm{mm} / \mathrm{rev}$.

$F a$ Feed force, N.

Fr Thurst force, $\mathrm{N}$.

Fv Tangential force, $\mathrm{N}$.

$H$ Workpiece hardness.

$H R C$ Rockwell hardness.

$R a$ Surface roughness, $\mu \mathrm{m}$.

Rt Total roughness, $\mu \mathrm{m}$.

$R z$ Mean depth of roughness, $\mu \mathrm{m}$.

$V c \quad$ Cutting speed, $\mathrm{m} / \mathrm{min}$.

$\alpha \quad$ Clearance angle, degree.

$\gamma \quad$ Rake angle, degree.

$\lambda$ Inclination angle, degree.

$\chi \quad$ Major cutting edge angle, degree.

\section{References}

Aouici H, Yallese M A, Fnides B and Mabrouki T 2010 Machinability investigation in hard turning of AISI H11 hot work steel with CBN tool. Mechanika 6(86): 71-77

Bouacha K, Yallese M A, Mabrouki T and Rigal J-F 2010 Statistical analysis of surface roughness and cutting forces using response surface methodology in hard turning of AISI 52100 bearing steel with CBN tool. J. Refr. Metals. \& Hard Mater. 28: 349-361

Çaydas U 2009 Machinability evaluation in hard turning of AISI 4340 steel with different cutting tools using statistical techniques. J. Eng. Mf. 224(7): 1034-1455

Chen L 2008 Study on prediction of surface quality in machining process. J. Mater. Process. Technol. 205: 439-450

Chiang K T 2008 Modeling and analysis of the effects of machining parameters on the performance characteristics in the EDM process of $\mathrm{Al}_{2} \mathrm{O}_{3}+$ TiC mixed ceramic. Int. J. Adv. Mf. 37: 523-533

Dilbag S P and Venkateswara R 2007 A surface roughness prediction model for hard turning process. Int. J. Adv. Mf. Technol. 32: 1115-1124

Drawish S M 2000 The impact of the tool material and the cutting parameters on surface roughness of supermet 718 nickel superalloy. J. Mater. Process. Technol. 97: 10-18

Dureja V S, Gupta V K, Sharma V S and Dogra M 2009 Design optimization of cutting conditions and analysis of their effect on tool wear and surface roughness during hard turning of AISI H-11 steel with a coated-mixed ceramic tool. J. Eng. Mf. 223: 1441-1450

El Baradie M A 1997 Surface roughness prediction in the turning of high strength steel by factorial design of experiments. J. Mater. Process. Technol. 67: 55-61

Feng C X 2001 An experimental study of the impact of turning parameters on surface roughness. Proceedings of the 2001, Industrial Engineering Research Conference, Paper $\mathrm{N}^{\circ} 2036$

Fnides B, Aouici H and Yallese M A 2008 Cutting forces and surface roughness in hard turning of hot work steel X38CrMoV5-1 using mixed ceramic. J. Mechanika 2(70): 73-78

Horng J T, Liu N M and Chiang K T 2008 Investigation the machinability evaluation of Hadfield steel in the hard turning with $\mathrm{Al}_{2} \mathrm{O}_{3} / \mathrm{TiC}$ mixed ceramics tool based on the response surface methodology. J. Mater. Process. Technol. 208: 532-541

Huang Y, Chou K, Liang S Y 2006 CBN tool wear in hard turning: a survey on research progresses. Int. J. Adv. Mf. Tochnol. 35: 443-453 
König W, Hochschule T, Komanduri R, Schenectady D and Tonshoff, H K 1984 Machining of hard materials. Ann. C1RP 33(2): 417-427

Kirby E D, Zhang Z and Chen J C 2004 Development of An Accelerometer based surface roughness Prediction System in Turning Operation Using Multiple Regression Techniques. J. Indus. Technol. 20(4): $1-8$

Lalwani D I, Mehta N K and Jain P K 2008 Experimental investigations of cutting parameters influence on cutting forces and surface roughness in finish hard turning of MDN250 steel. J. Mater. Process. Technol. 206: $167-179$

Lima J G, Ávila R F, Abrão A M, Faustino M and Davim J P 2005 Hard turning: AISI 4340 high strength low steel and AISI D2 cold work tool steel. J. Mater. Process. Technol. 169: 388-395

Özel T, Karpat Y, Figuelra L and Davim J P 2007 Modeling of surface finish and tool flank wear in turning of AISI D2 steel with ceramic wiper inserts. J. Mater. Process. Technol. 189: 192-198

Özel T, Hus T K and Zerne E 2005 Effects of cutting edge geometry, workpiece hardness, feed rate and cutting speed on surface roughness and forces in finish turning of hardened AISI H13 steel. Int. J. Adv. Manuf. Technol. 25: 262-269

Sahin Y and Motorcu A R 2005 Surface roughness model for machining mild steel with coated carbide tool. J. Mater. \& Design 26: 321-326

Singh H and Kumar P 2006 Optimizing feed force for turned parts through the Taguchi technique. Sadhana 3(6): 671-681

Suresh P, Rao P V and Deshmukh S G 2002 A genetic algorithmic approach for optimization of surface roughness prediction model. Int. J. Mach. Tools Mf. 42: 675-680

Tamizharasan T, Selvaraj T and Noorul A 2006 Analysis of tool wear and surface finish in hard turning. Int. Adv. Mf. Technol. 28: 671-679

Thiele J and Melkote S 1999 Effect of cutting edge geometry and workpiece hardness on surface generation in the finish hard turning of AISI 52100 Steel. J. Mater. Process. Technol. 94: 216-226

Yallese M A, Chaoui K, Zeghib N, Boulanouar L and Rigal J F 2009 Hard machining of hardened bearing steel using cubic boron nitride tool. J. Mater. Process. Technol. 209: 1092-1104 